
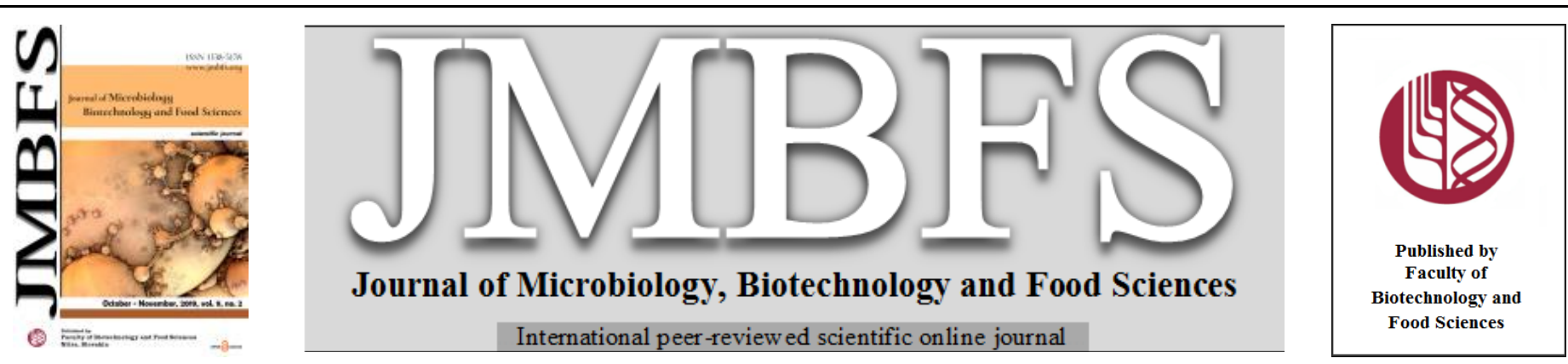

\title{
METHODOLOGICAL APOPROACH EXEMPLIFIED BY LACTOCOCCI: OPTIMIZATION OF BIOTECHNOLOGICAL PROCESSES BY MEANS OF ELISA VIA LOCALIZATION OF THE TARGET BIOPOLYMER AND SELECTION OF DURATION OF CULTURE GROWTH AND MEDIA COMPOSITION PROVIDING MAXIMUM YEALD
}

\section{Elena Kiseleva ${ }^{1 *}$, Konstantin Mikhailopulo ${ }^{1}$, Galina Novik ${ }^{2}$}

\author{
$\operatorname{Address(es):~}$ \\ ${ }^{1}$ Institute of Bioorganic Chemistry, National Academy of Sciences of Belarus, Academician V.F.Kuprevich Street 5/2, 220141 Minsk, Republic of Belarus. \\ ${ }^{2}$ Belarusian collection of non-pathogenic microorganisms, Institute of Microbiology, National Academy of Sciences of Belarus, Academician V.F.Kuprevich Street 2, \\ 220141 Minsk, Republic of Belarus.
}

*Corresponding author: epkiseleva@yandex.by

doi: 10.15414/jmbfs.2019.9.2.338-344

ARTICLE INFO

Received 31. 5. 2019

Revised 17. 6. 2019

Accepted 4. 8. 2019

Published 1. 10. 2019

Regular article

open $\mathcal{O}$ access

\begin{abstract}
Enzyme-linked immunoassay (ELISA) is suitable as a method for detection and quantification of bacterial biopolymers at condition that they have antigenic properties. Using of ELISA allows optimizing biotechnological processes via selection of the strain producing the biolimer of interest, localization of the biopolymer and selection of duration of culture growth and media composition providing maximum yeald. We elaborated the methodology for studing the time dependence of specific concentration $\left(C_{\mathrm{sp}}\right)$ (calculated per cell) of the biopolymer of interest in cell fractions and culture media. The methodology includes four points: $(i)$ selecting of bacteria applicable as objects of study; (ii) obtaining, preliminary preparation and quantification of cell fractions and specimens of culture media; (iii) design of ELISA suitable for studing $C_{\mathrm{sp}}$ of intracellular antigens (contained in cell-wall free fraction), cell wall antigens and secretory antigens; ( $i v$ ) methods for converting of ELISA data into $C_{\mathrm{sp}}$ (in conventional units) and explanation of the results. We present the methodology using 4 strains of lactococci and rabbit polyclonal antibodies (PAb) against genus-specific antigens of Lactococcus lactis

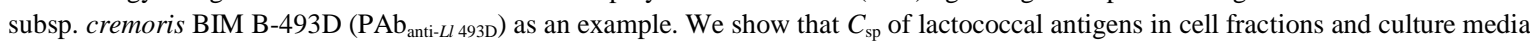
depends on strain, media composition and duration of culture growth. Distribution of antigens between cell fractions and media and time-dependance of $C_{\mathrm{sp}}$ is unpredictable and for each strain/media should be determined individually. The methodology is suitable for any bacterium and any well-defined antigen under the condition that either PAb or mouse monoclonal antibodies specific for this antigen will be used. The methodology will find an application in biotechnology and research studies.
\end{abstract}

Keywords: ELISA, polyclonal antibodies, bacterial antigens, time dependence of antigen synthesis, time dependence of antigen secretion, biotechnology

\section{INTRODUCTION}

The goal of numerous biotechnological processes is obtaining of compounds synthesized in bacterial cells. Optimization of such processes includes selection of the strain producing the biolimer of interest, localization of the biolimer (cytoplasm/cell wall/culture medium) and selection of the composition of the culture medium and the stage of culture growth to ensure its maximum yield at minimal cost. Useful biopolymers synthesized in bacterial cells (biosurfactants, bacteriocins, enzymes, recombinant human proteins, etc. (Balciunas et al., 2013; Gurung et al., 2013; Adrio and Demain, 2014; Yang et al., 2014; Vijayakumar and Saravanan, 2015; López-Cuellar et al., 2016; Singh et al., 2016; Chikindas et al., 2017; Shigemori et al., 2017) are immunogens; lowmolecular weigth bacterial compounds become immunogens after conjugation with carriers (Hermanson, 2008). The possibility of producing antibodies specific for high/low-molecular weigth compounds synthesized in bacterial cells allows the detection of these compounds and their quantification by immunoassay methods.

In current study we present a methodology for studying the time dependence of specific concentration $\left(C_{\mathrm{sp}}\right)$ (calculated per cell) of antigens of nonpathogenic microorganisms in cell fractions and culture media. To simplify the presentation of the methodology, we use as an example 4 selected strains of Lactococcus lactis and rabbit polyclonal antibodies (PAb) obtained with whole bacterial cells of L. lactis BIM B-493D as a immunogen ( $\left.\mathrm{PAb}_{\text {anti- } L \text { 493D }}\right)$. Since the immunogen had a complex chemical composition, $\mathrm{PAb}_{\text {anti- } L l \text { 493D }}$ are potentially capable of forming immune complexes with numerous, if not all, antigens of L. lactis BIM B-493D and related bacteria. We did not purpose to identify these antigens, and therefore in the text we use the term "antigens of unknown nature and structure". Important, that our methodology can be used to study time dependance of synthesis and secretion of any well-defined antigen at condition that PAb or mouse monoclonal antibody specific for this antigen is used instead of $\mathrm{PAb}_{\text {anti- } L l}$ 493D.

The choice of $L$. lactis as a model for the study of antigens of nonpathogenic microorganisms is due to the extensive use of these bacteria in various industries and medicine. Natural strains of L. lactis find application as starter cultures in the production of fermented milk products, for example, sour cream, curdled milk and buttermilk, as well as cottage cheese and cheese (Coffey and Ross, 2002; Yadav et al., 2009; Frece et al., 2014). In addition, L. lactis is a natural producer of bacteriocin nisin used as a preserving agent in the food industry and an antimicrobial drug in dentistry (Jozala et al., 2005).

The genome of L. lactis is well studied, which makes it possible to obtain and use recombinant strains of this microorganism. In particular, recombinant strains of L. lactis with the built-in alanine dehydrogenase gene (CF 1.4.1.1) and the deleted lactate dehydrogenase gene (CF 1.1.1.27) are used in the production of Lalanine (Hols et al., 1999) applicable as a sugar substitute in dairy products. Strains that produce human interleukin 10 are used in the treatment of Crohn's disease (Braat et al., 2006), and strains carrying the built-in pathogen genes and allergens are promising for the development of vaccines that are administered intranasally and orally (Medina et al., 2010; Asensi et al., 2013; Ai et al, 2014). Recombinant strains of $L$. lactis are used to produce bovine lactoferrin for the prevention of sepsis (Shigemori et al., 2017), an amylase inhibitor for therapy of diabetes (D'Souza et al., 2012), etc.

Note, that studies of antigenes of nonpathogenic microorganisms, including human intestinal symbionts and probiotics are significant in themselves, regardless of the needs of biotechnology, because in contrast to antigens of pathogenic microorganisms, the chemical nature and structure of these biopolymers, their location in the cell and dynamics of synthesis remain, as a 
rule, unknown. L. lactis is not considered to be a human symbiotic (Heilig et al., 2002), but it is constantly present in the intestines in transit entering the body as a part of dairy and plant products, and selected strains of the bacterium are known as a probiotics. The beneficial influence of L. lactis on human health includes their adherence to the digestive tract, synthesis of vitamins, decrease of allergy to milk proteins and intolerance to lactose, and reducing level of blood cholesterol. Indeed, anti-diabetic activity, anti-mutagenic/dysmutagenic activity and immunomodulatory activity of selected $L$. lactis strains was shown (Yadav et al., 2009).

Aim - to develop a methodology for studying the time dependence of specific concentration $\left(C_{\mathrm{sp}}\right)$ (calculated per cell) of antigens of nonpathogenic microorganisms in cell fractions and culture media by the example of lactococci using rabbit $\mathrm{PAb}_{\text {anti-Ll } 493}$ obtained with with whole cells of $L$. lactis BIM B-493 D as an immunogen

\section{MATERIALS AND METHODS}

\section{Bacteria}

The physiologically active cultures of $L$. lactis BIM B-493D ( $L l$ 493D), BIM B 424 ( $L l$ 424), BIM B-132 ( $L l$ 132) and BIM B-922 ( $L l$ 922) after the second $24 \mathrm{~h}$ incubation were used as inoculums. All strains were incubated 12, 24 and $48 \mathrm{~h}$ in $50 \mathrm{ml}$ of MRS and $50 \mathrm{ml}$ of MRS 2-fold diluted by water ((medium 1 and medium 2, respectively).

\section{Preparation of specimens}

Cells (24 samples) were separated by centrifugation at $2000 \mathrm{~g}$ for $20 \mathrm{~min}$. Culture media after growth of culture and removal of cells was designated as cultural liquid (CL). $3 \mathrm{~mL}$ of each $\mathrm{CL}$ specimen $\left(\mathrm{CL}_{12}, \mathrm{CL}_{24}, \mathrm{CL}_{48}\right.$; the numeral corresponds to the time length of culture growth, $\mathrm{h}$ ) was lyophilized. Cells were washed $(3 \times 50 \mathrm{~mL})$ with $0.15 \mathrm{M} \mathrm{NaCl}, 0.01 \mathrm{M}$ sodium phosphate, $\mathrm{pH} 7.5$ (buffer 1), suspended in buffer $1(1 \mathrm{~mL})$, manually homogenized (Wheaton, USA) and ultrasonicated on ice using Branson Digital Sonifier 450 (Branson, USA) as it was done in our recent study (Kiseleva et al., 2017). The cell wall fraction $(\mathrm{CW})$ and cell wall free fraction $(\mathrm{CFF})$ were obtained by centrifugation at $13000 \mathrm{~g}$ for $30 \mathrm{~min}$ using Eppendorf Mini Spin plus (Eppendorf AG, Germany). $\mathrm{CW}$ specimens and CFF specimens were designated $\mathrm{CW}_{12}, \mathrm{CW}_{24}$ $\mathrm{CW}_{48}$ and $\mathrm{CL}_{12}, \mathrm{CL}_{24}, \mathrm{CL}_{48}$, respectively; the numeral corresponds to the time length of culture growth, $\mathrm{h}$ ). The value of the optical density at $260 \mathrm{~nm}$ in a cuvette with $1 \mathrm{~cm}$ optical path length $\left(A_{260 \mathrm{~nm}, 1 \mathrm{~cm}}\right)$ of each CFF specimen was measured using spectrophotometer Specord (Carl Zeiss, Germany). The amount of total nucleic acids (tNA) (conventional units) in each CFF specimen was calculated as product of $A_{\mathrm{nm}, 1 \mathrm{~cm}}$ value (AU) and the corresponding CFF volume $(\mathrm{mL})$. Each CW specimen was weighted using analytical balance CPA225D (Sartorius, Germany). Specimens of CFF, CW and CL (24 pieces of each) were stored at $-20{ }^{\circ} \mathrm{C}$.

Antiserum referred to below as PAb anti- Ll 493D was obtained by immunization of rabbits with whole cells of $L l 493 \mathrm{D}$ (Ezubetz et al., 2014) and stored at $-70^{\circ} \mathrm{C}$.

\section{Purification of antibodies to $L l$ 493D antigens}

$\mathrm{PAb}_{\text {anti- } L l \text { 493D }}$ were used for isolation of total human immunoglobulins (Ig) enriched with antibodies to $L l$ 493D antigens ( $\left.\operatorname{Ig}_{\text {anti- } L l ~ 493 \mathrm{D}}\right)$ by method of Perosa et al. (Perosa et al. 1990). Optical density at $280 \mathrm{~nm}$ was measured with spectrophotometer Specord (Carl Zeiss, Germany). $A_{280 \mathrm{~nm}, 1 \mathrm{~cm}, 1 \mathrm{mg} / \mathrm{ml}}=1.35$ was used to calculate concentration of $\operatorname{Ig}_{\text {anti- } L l ~ 493 \mathrm{D} \text {. }}$

ELISA was performed using 96-well high binding microplates Microlon (Greiner bio-one, Germany). Buffer solutions. Buffer 1 was used for wells washing. Buffer 2 (buffer 1 without $0.15 \mathrm{M} \mathrm{NaCl}$ ) was used for antigens immobilization. Either buffer 3 or buffer 4 (buffer 1 plus either $1 \mathrm{~g} / \mathrm{L}$ or $3 \mathrm{~g} / \mathrm{L}$ bovine serum albumin (BSA)) were used as incubation buffers. Study of the dynamics of $C_{s p}$. of lactococcal antigens in $C F F, C L$ and $C W$. 1st stage of ELISA was performed as described in paragraph Results and discussion. 2nd stage of ELISA was performed and $A_{450}$ values were measured as it was done in our recent study (Kiseleva et al., 2017).

\section{RESULTS AND DISCUSSION}

We present a methodology for studying the time dependence of $C_{\mathrm{sp}}$ (per cell) of bacterial antigens in cell fractions and culture media.

The methodology includes 4 points:

(i) selecting of bacteria applicable as objects of study;

(ii) obtaining, preliminary preparation and quantification of cell fractions and specimens of CL;

(iii) design of ELISA suitable for studing $C_{\mathrm{sp}}$ of intracellular antigens (contained in $\mathrm{CFF}$ ), cell wall antigens and secretory antigens;

(iv) methods for converting of ELISA data into $C_{\mathrm{sp}}$ (in conventional units) and explanation of the results.

To simplify the presentation, we use as an example 4 strains of L. lactis selected in accordance with point $(i)$ and $\mathrm{PAb}_{\text {anti- } L l \text { 493D }}$ obtained with whole cells of $L$. lactis BIM B-493D as immunogen. We used CW, CFF (the term used to designate a combination of a cytoplasm and the components of $\mathrm{CW}$, passing into solution when the cells are destroyed by ultrasound) and CL as sources of antigens.

The concept of the distribution of bacterial antigens in the cell - environment system

The theoretical basis for this work was the concept of the distribution of bacteria antigens in the cell - media system. It consist in the fact that all antigens are biopolymers synthesized inside the cell and then either distributed between the cytoplasm and the system plasma membrane - $\mathrm{CW}$ or secreted into the external environment (products of primary secretion) in accordance with their biologica functions. In addition, the entry of antigens into the external environment can results from the detachment of the components of the outer part of the $\mathrm{CW}$ (the protein-polysaccharide complex) from the surface of living cells, which occurs as CW thickness increases during the aging of cells (products of secondary secretion). The third reason for the entry of antigens into the externa environment is the natural death of cells. In accordance with the concept, the highest possible antigen set is in CFF. With this in mind, namely CFF was used for immobilization on a solid phase in competitive ELISA tests presented below.

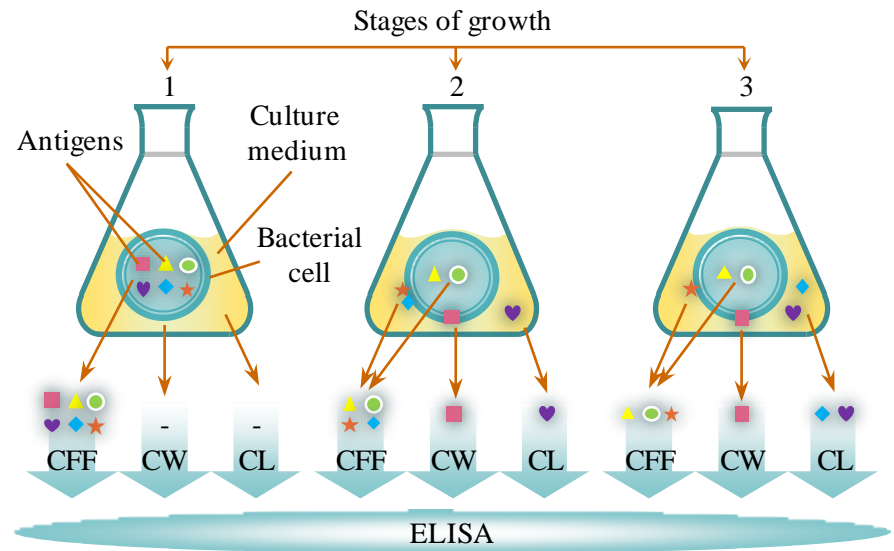

Figure 1 Dependence of distribution of bacterial antigens in the "cell environment" system from the stage of culture growth

In view of the above, the distribution of bacterial antigens in the "cell environment" system depends on the stage of culture growth (Figure 1).

\section{Main points of methodology for studying the time dependence of $C_{s p}$ (per cell) of bacterial antigens in cell fractions and culture media}

\section{Point $i$. Selecting of bacteria applicable as objects of study}

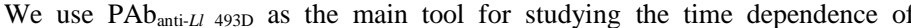
synthesis and secretion of bacterial antigens. Therefore, the subject of the study may be a strain-immunogen and strains of related microorganisms containing antigens identical or similar to the antigens of strain-immunogen. The values of the cross reaction of $\mathrm{PAb}_{\text {anti- } L l \text { 493D }}$ with antigens of bacteria were determined. They must be at least $10 \%$ to recognize the bacterium as suitable for use as an object of study.

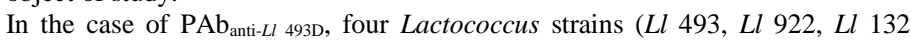
Ll 424) (Table 1) were selected as suitable for the study. 
Table 1. Cross reaction values calculated for $\mathrm{PAb}_{\text {anti-Ll } 493}$

\begin{tabular}{|c|c|c|c|}
\hline \multicolumn{3}{|l|}{ Bacteria } & \multirow{2}{*}{ Cross-reaction, $\%$} \\
\hline Genus & Species and strain & Abbreviation & \\
\hline \multirow{5}{*}{ Lactococcus } & L. lactis BIM B-493D $\mathrm{D}^{1,2}$ & $L l 493 \mathrm{D}^{1,2}$ & 100 \\
\hline & L. lactis BIM B- $424^{2}$ & Ll $424^{2}$ & 62 \\
\hline & L. lactis BIM B- $132^{2}$ & Ll $132^{2}$ & 40 \\
\hline & L. lactis BIM B- $922^{2}$ & $L l 922^{2}$ & 25 \\
\hline & L. lactis BIM B-426 & Ll 426 & $<1$ \\
\hline \multirow{3}{*}{ Streptococcus } & S. thermophilis BIM B-527 & St 527 & 4.9 \\
\hline & S. thermophilus BIM B-722 & St 722 & $<1$ \\
\hline & S. thermophilis BIM B-528 & St 528 & $<1$ \\
\hline \multirow{6}{*}{ Enterococcus } & E. faecalis BIM B-1012 & $E f 1012$ & $<1$ \\
\hline & E. faecium BIM B-716 & Efm 716 & $<1$ \\
\hline & E. faecium BIM B-717 & Efm 717 & $<1$ \\
\hline & E. faecium BIM B-718 & Efm 718 & $<1$ \\
\hline & E. faecium BIM B-529 & Ef 529 & $<1$ \\
\hline & E. faecium BIM B-720 & $E f 720$ & $<1$ \\
\hline Lactobacillus & L. plantarum BIM B-423D & $L p 423 \mathrm{D}$ & $<1$ \\
\hline
\end{tabular}

Bacteria of the selected strains were grown on two media: standard MRS culture medium (medium 1), and medium 2 obtained by double dilution of MRS with distilled water. The duration of cultivation was $12 \mathrm{~h}, 24 \mathrm{~h}$ and $48 \mathrm{~h}$.

Point ii. Obtaining, preliminary preparation and quantification of cell fractions and CL specimens

Cells of selected strains were precipitated by centrifugation; each CL specimen

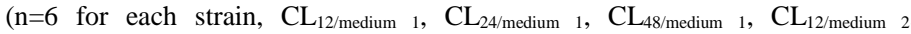

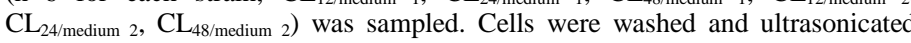
followed by centrifugation; CFF specimens ( $\mathrm{n}=6$ for each strain) and CW specimens ( $\mathrm{n}=6$ for each strain) were obtained as supernatant and precipitate, respectively and named in the same way as the CL specimens. Scheme for obtaining CL, CFF and CW specimens was shown in our recent study (Kiseleva et al., 2017).

Quantification of cell fractions and CL specimens included:

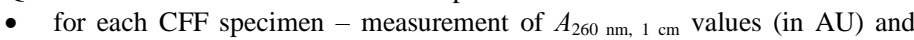
volume (in $\mathrm{mL}$ ); product of $A_{\mathrm{nm}, 1 \mathrm{~cm}}$ and the corresponding CFF volume give the amount of tNA (in conventional units);

- for each CW specimen - measurement of weight (in $\mathrm{mg}$ );

- for each CL specimen - measurement of volume (in $\mathrm{mL}$ )

Preliminary preparation of CL specimens includes calculation of the dissolution factors (DF). This is only necessary if the tested strains were grown in different volumes of a culture medium. $\mathrm{DF}_{\mathrm{n}}=\mathrm{b}_{\mathrm{n}} / \mathrm{a}$, where a - maximum volume corresponding to strain designated $\mathrm{A}, \mathrm{b}_{\mathrm{n}}$ - volume corresponding to each other strain $1-n .3 \mathrm{~mL}$ of CL specimen corresponding to strain $A$ and $\left(3 \times \mathrm{DF}_{n}\right) \mathrm{mL}$ of CL specimen corresponding to each other strain are transferred to vials and lyophilized. Immediately before analysis, an equal amount of water $(300 \mu \mathrm{L})$ is added to all vials and mixed until the lyophilized substances are completely dissolved. Thus, we obtain 10 -fold concentrates of CL specimens preliminary reduced to an equal volume of culture medium.

The quantitative characteristics of each culture of four Lactococcus strains required for $(i)$ "equalization" of CFF specimens for ELISA, (ii) the mathematical processing of ELISA data and (iii) the interpretation of the results are presented in Figure 2. Amount of tNA (in conventional units) is proportional to a number of bacterial cells. CW weight is function of a number of bacterial cells and a thickness of the cell wall.

The data shown in Figure 2 indicate that a decrease in the nutrient concentration in the culture medium leads to a restriction of growth of all used strains. In medium 1, duration of the logarithmic phase was less than $12 \mathrm{~h}$, since there was no increase in the amount of tNA in the CFF specimens of the 4 strains in the period of $12 \mathrm{~h}-24 \mathrm{~h}$. The dying phase occurred at $48 \mathrm{~h}$, which is especially evident for strains $L l 132$ and $L l 424$ since the amount of tNA in CFF specimens of the strains (and hence the number of cells) at $48 \mathrm{~h}$ was less than $50 \%$ of that in CFF specimens corresponding to $12 \mathrm{~h}$ of culture growth.
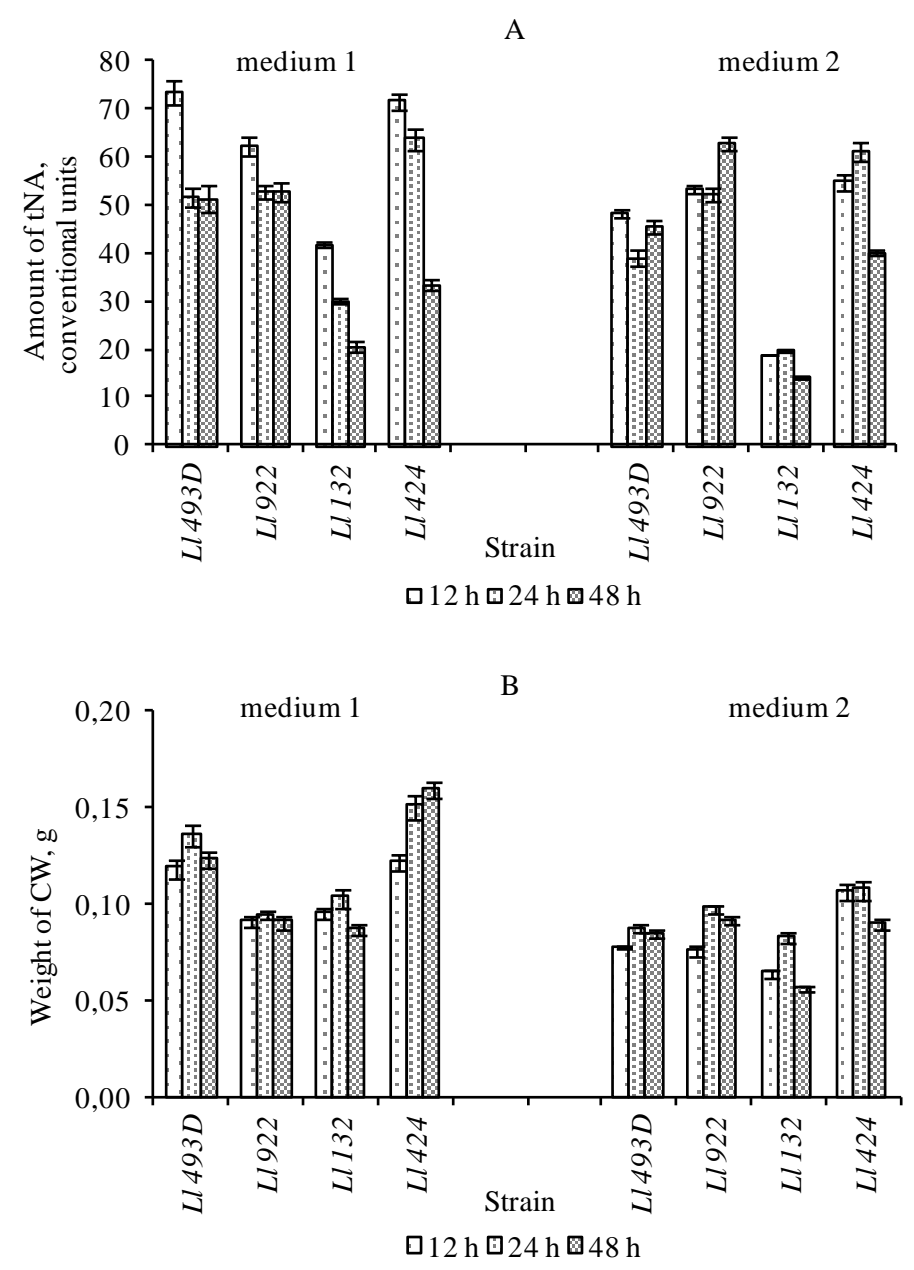

Figure 2 The quantitative characteristics of cell fractions of 4 strains of lactococci. A and B - tNA amount in CFF and weight of CW, respectively. (1248) $\mathrm{h}$ - time length of culture growth in medium 1 and medium 2 . Three independent experiments were performed. Values are means \pm SD.

In medium 2, the logarithmic phase also lasted less than $12 \mathrm{~h}$, because the amoun

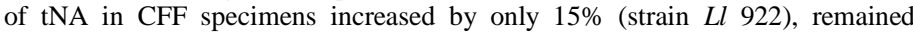
virtually unchanged (strains $\mathrm{Ll}$ 493D and $L l$ 132) or decreased (strain $\mathrm{Ll} \mathrm{424}$ ) during the observation period $(12 \mathrm{~h}-48 \mathrm{~h})$, which corresponds to the late stationary phase and the dying phase of the culture, respectively.

The increase in the total weight of $\mathrm{CW}$ occurring during the period of $12 \mathrm{~h}-24 \mathrm{~h}$ in both media (Figure 2) was due to an increase in their thickness, rather than an 
increase in the number of cells (with the exception of the strain $L l 424$ growing in medium 2). A decrease in the value of this parameter was observed in the period

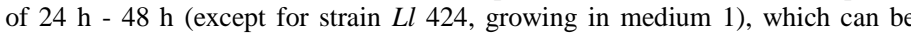
explained by two reasons. The first reason is the natural death of cells (on conditions that $\mathrm{CW}$ weight decreases and amount of tNA decreases simultaneously, for example, in CFF specimens of strain $\mathrm{Ll} 424$ growing in medium 2 and strain $L l$ B-132 growing in medium 1 and medium 2). The second reason is the separation from the cell surface and migration into environment of $\mathrm{CW}$ components. It occurs when $\mathrm{CW}$ weight decreases and amount of tNA increases/remains unchanged simultaneously (e.g. in CFF specimens of strain $L l$ 493D in both media and strain $\mathrm{Ll} 922$ in medium 2).

Points $i i i$ - $i v$. Design of ELISA, methods for converting of ELISA data into $C_{\text {sp }}$ (in conventional units) and explanation of the results

The rabbit antiserum designated above as $\mathrm{PAb}_{\text {anti- } L l ~ 493 \mathrm{D}}$ was used for isolation of total Igs enriched with appropriate PAbs reffered to below as $\operatorname{Ig}_{\text {anti- } L l \text { 493D. In all }}$ ELISA tests detection of immune complexes " $\operatorname{Ig}_{\text {anti- } L l \text { 493D }}$ - immobilized antigen" was performed by means of conjugate of sheep PAb against rabbit $\mathrm{Ig}$ with horseradish peroxidase. The 3,3',5,5'-tetramethylbenzidine was used as a peroxidase substrate. $A_{450}$ values were detected.

\section{The time dependence of $C_{s p}$ (calculated per cell) of intracellular antigens}

To compare the time dependence of $C_{\mathrm{sp}}$ (calculated per cell) of intracellular antigens of lactococci, the following approach was used. We diluted CFF specimens to obtain pre-selected values $A_{260} \mathrm{~nm}, 1 \mathrm{~cm}$, equal to 0.1 , thereby "equalizing" the number of cells of each strain (per $1 \mathrm{~mL}$ of CFF) from which these antigens were obtained. Each pre-diluted CFF specimen was immobilized in a separate series of wells ( 24 series $=4$ strains $\times 2$ medium $\times 3$ terms of culture growth), $100 \mu \mathrm{L}$ per well. $\operatorname{Ig}_{\text {anti- } L l ~ 493 \mathrm{D}}(0.41-52.0 \mu \mathrm{g} / \mathrm{mL}$ in buffer $3 ; 100 \mu \mathrm{L}$ per well) were added to each well and incubated. The amount of immune complexes was directly proportional to the amount of antigens in immobilized CFF samples. The value of $A_{260 \mathrm{~nm}, 1 \mathrm{~cm}}$ in solution for immobilization of CFF specimens and the

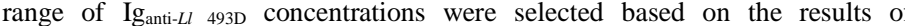
preliminary experiments. The criterion of selection was obtaining classical saturation curves having a pronounced "plateau". Typical data are shown in Figure 3 using strain $\mathrm{Ll}$ B-132 grown in medium 2 as an example. Similar saturation curves were obtained for each of the 4 strains grown in medium 1 and medium 2 (data not shown).
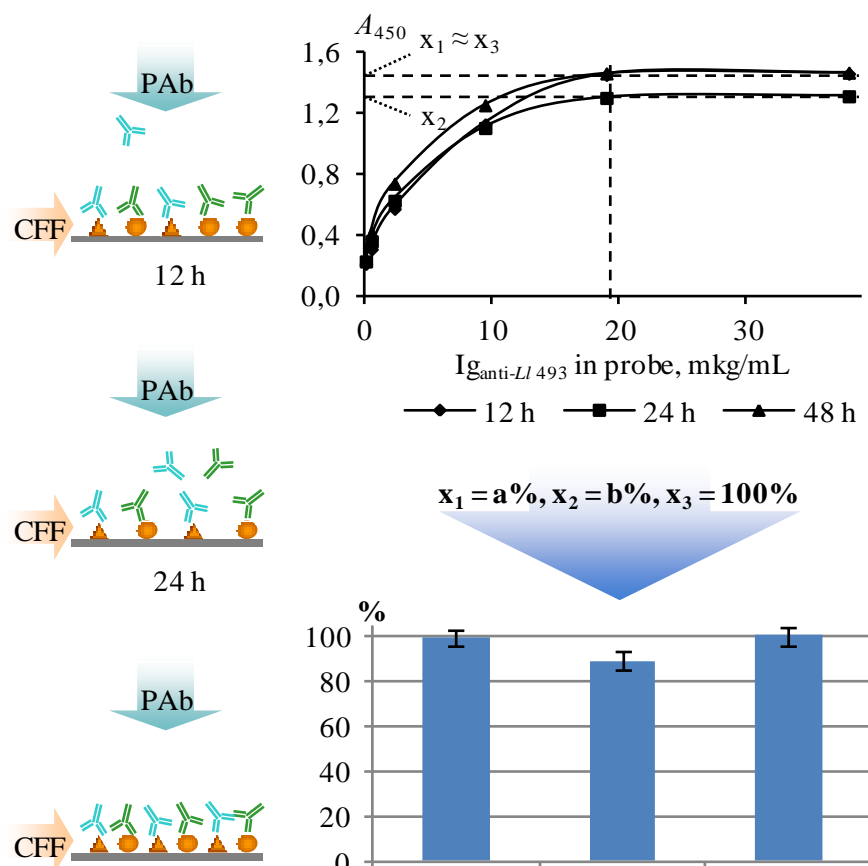

$48 \mathrm{~h}$

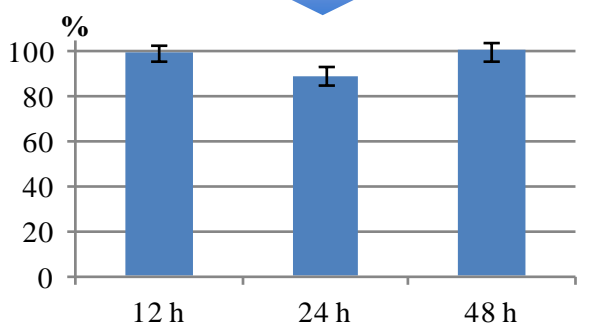

Figure 3 The time dependence of $C_{\mathrm{sp}}$ (calculated per cell) of intracellular antigens: design of ELISA, experimental data and their processing. Strain $L l 132$ grown in medium 2 was used as an example. Term PAb means $\mathrm{Ig}_{\text {anti- } L l ~ 493 \mathrm{D}}$. Three independent experiments were performed. Values are means \pm SD.

The data were processed as follows. On each graph containing three curves, the values of $A_{450}$ were determined for the experimental points corresponding to the output of the curves on the plateau. The maximum $A_{450}$ value was taken as $100 \%$. Two other $A_{450}$ values were converted into percentages. The calculated values were designated as $\mathrm{x}_{1}-\mathrm{x}_{3}$, where $1-3$ are $12 \mathrm{~h}-48 \mathrm{~h}$ of culture growth, respectively. The values were proportional to the $C_{\mathrm{sp}}$ of intracellular antigens (per cell) and presented in the form of histograms in Figure 4, CFF.

The data shown in Figure 4, CFF suggest that the values of $C_{\mathrm{sp}}$ (per cell) of CFF antigens changes by no more than $20 \%$ for strains $L l 493 \mathrm{D}, \mathrm{Ll} 132$ and $\mathrm{Ll} 922$ during the observation period $12 \mathrm{~h}-48 \mathrm{~h}$, irrespective of the culture medium. For strain $\mathrm{Ll} 424$ grown in medium 1, the change in $C_{\mathrm{sp}}$ (per cell) of CFF antigens is $(6-8) \%$; although in medium $2,24 \mathrm{~h}-48 \mathrm{~h}, C_{\mathrm{sp}}$ (per cell) increases by $40 \%$. It is logical to assume that the more pronounced changes in value of $C_{\mathrm{sp}}$ (per cell) of CFF antigens occurred during the logarithmic phase of culture growth, the duration of which was shorter than anticipated when planning the work.

Thus, the dynamics of $C_{\mathrm{sp}}$ (per cell) of CFF antigens depends on the strain and culture medium. The reason for the increase in $C_{\mathrm{sp}}$ (per cell) of CFF antigens is their synthesis. The reason for the decrease in $C_{\mathrm{sp}}$ (per cell) of CFF antigens is their incorporation into the $\mathrm{CW}$ and secretion into the external environment.

\section{The time dependence of $C_{s p}$ (calculated per cell) of $C W$ antigens}

To compare the time dependence of $C_{\mathrm{sp}}$ (calculated per cell) of CW antigens, the following approach was used. Each pre-diluted CFF specimen of 4 strains ( $\mathrm{n}=$ 24) was immobilized from a solutions with pre-selected value of $A_{260 \mathrm{~nm}, 1 \mathrm{~cm}}$ equal to 0.025 in a separate series of wells; total 24 series of wells.

CW specimens were prepared for ELISA as follows. CFF specimen with minimal tNA amount was selected and corresponding CW specimen was suspended in 1 $\mathrm{mL}$ of buffer 2. The amount of buffer 2 (in $\mathrm{mL}$ ) to be added to other $\mathrm{CW}$ specimens $(n=23)$ were equal to corresponding $\mathrm{DF}_{\mathrm{n}}$ values calculated in the following way: $\mathrm{DF}_{\mathrm{n}}=\mathrm{d}_{\mathrm{n}} / \mathrm{c}$, where $\mathrm{c}-\mathrm{tNA}$ amount in the selected CFF specimen $d_{n}-t N A$ amount in another CW specimen. Thus, the volumes of CW suspensions were in the same proportion as the values of the amount of tNA in the corresponding $\mathrm{CFF}$ specimens, which allowed to "equalizing" $\mathrm{CW}$ suspensions by the number of cells of bacteria that were the sources of $\mathrm{CW}$.

All CW specimens $(n=24)$ were suspended to homogeneity to prepare a series of $B_{1}-B_{6}$ samples by successive dilution with buffer 2 . During the preparation of $B_{1}$ - $\mathrm{B}_{6}$ samples, each suspension was maintained in a homogeneous state. $0.2 \mathrm{~mL}$ of each $\mathrm{B}_{1}-\mathrm{B}_{6}$ sample (or $0.2 \mathrm{~mL}$ of buffer 2 used as $\mathrm{B}_{0}$ sample) and $0.1 \mathrm{~mL}$ of buffer 4 containing $22.5 \mu \mathrm{g} / \mathrm{mL}$ of $\operatorname{Ig}_{\text {anti- } L l ~ 493 \mathrm{D}}$ were mixed in eppendorf tubes and incubated for $2 \mathrm{~h}$ at room temperature with continuous stirring using a Multi Bio RS-24 (BioSun, Latvia). The complexes "antigens of CW - $\operatorname{Ig}_{\text {anti- } L l \text { 493D" were }}$ precipitated by centrifugation.

Each supernatant containing free $\mathrm{Ig}_{\text {anti- } L l \text { 493D }}$ was added into appropriate wells with corresponding $\mathrm{CFF}$ specimen $(100 \mu \mathrm{L}$ per well) and incubated to form immune complexes "antigens of CFF - $\mathrm{Ig}_{\text {anti- } L l \text { 493D". The amount of immune }}$ complexes was inversely to the amount of antigens in the $\mathrm{CW}$ suspension. 


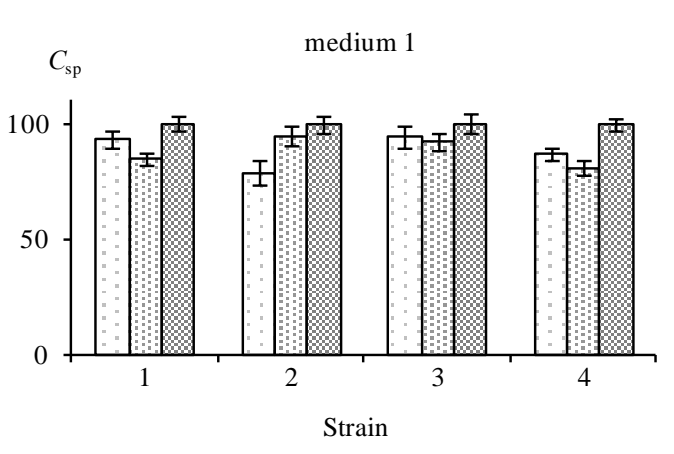

$\mathrm{CFF}$
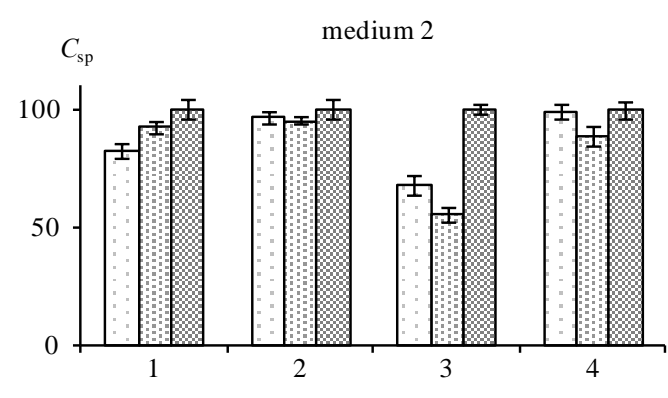

$\mathrm{CW}$
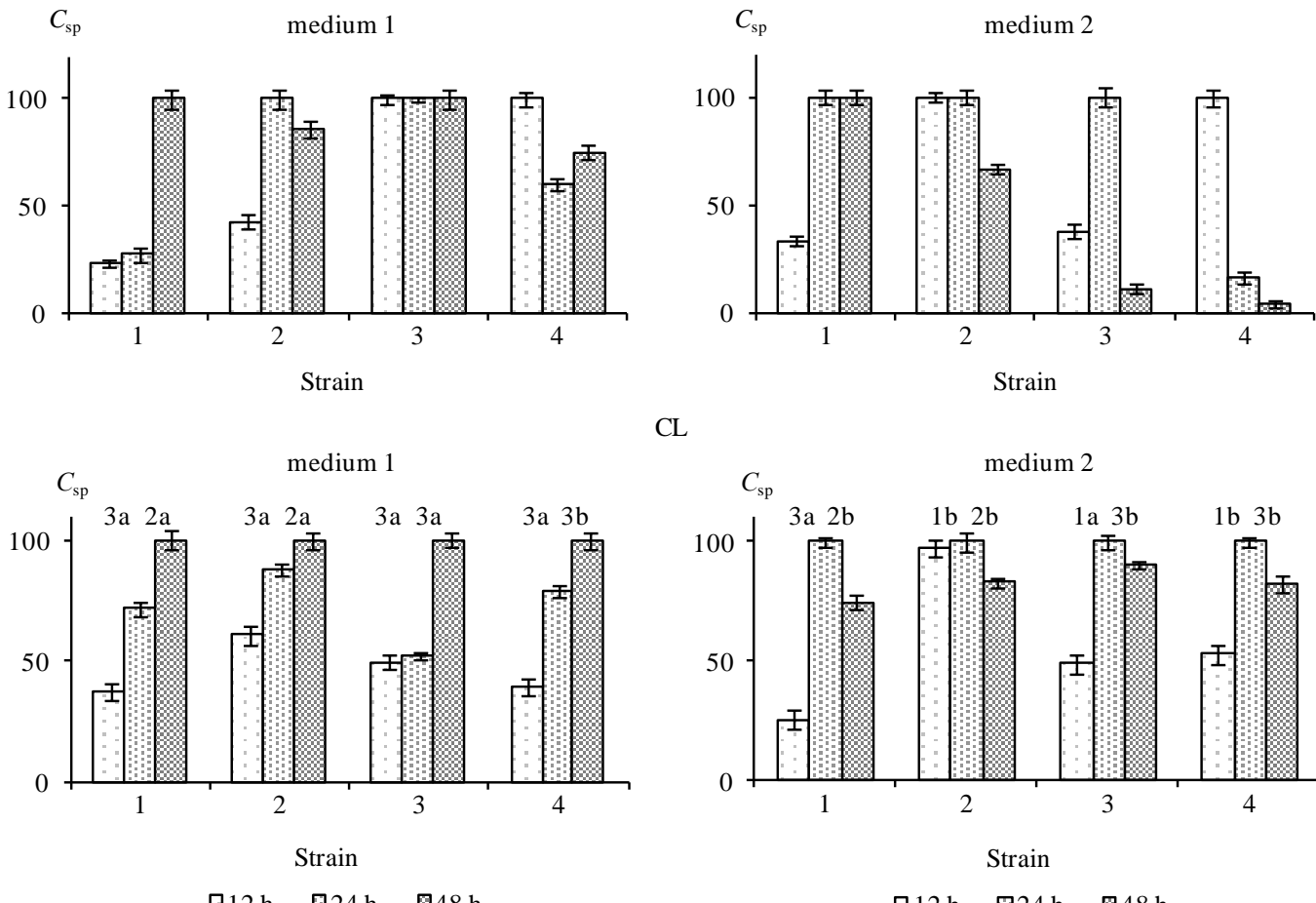

CL

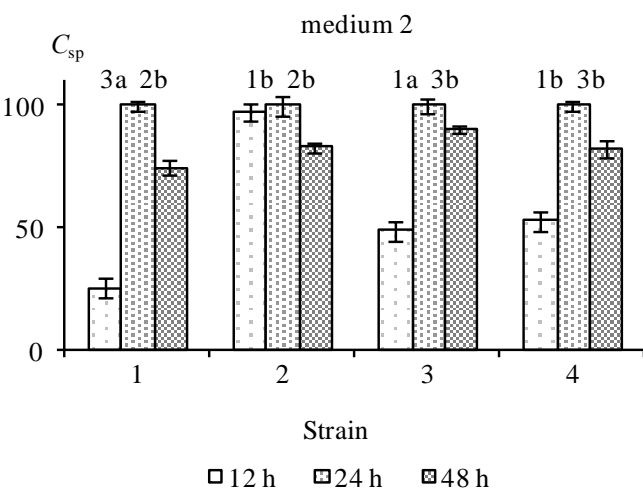

$\mathbf{1}$ primary secretion

2 secondary secretion

3 secondary secretion and/or natural cell death

a - tNA $\uparrow, C W$ const

a - tNA const, CW $\downarrow$

$-\mathrm{tNA} \downarrow, \mathrm{CW} \uparrow$

$\mathrm{b}$ - tNA const, $\mathrm{CW} \uparrow$

$\mathrm{b}-\mathrm{tNA} \uparrow, \mathrm{CW} \downarrow$

$\mathrm{b}-\mathrm{tNA} \downarrow, \mathrm{CW} \downarrow$

Figure 4 Dependence of $C_{\text {sp }}$ (per cell) of antigens contained in CFF, CW and CL of four Lactococcus strains from the time length of culture growth in medium 1 and medium 2. Strains $(1-4)$ are $L l$ 493D, $L l 922, L l 424$ and $L l 132$, respectively.

The value of $A_{260 \mathrm{~nm}, 1 \mathrm{~cm}}$ in solution for immobilization of CFF specimens, $\operatorname{Ig}_{\text {anti- } L}$ 493D concentration and the volumes of $\mathrm{CW}$ suspensions used to prepare a series of $\mathrm{B}_{1}-\mathrm{B}_{6}$ samples were selected based on the results of preliminary experiments. The criterion of selection was obtaining classical curves of competitive ELISA (in coordinates $\mathrm{OX}$ axis $-\mathrm{B}_{\mathrm{n}} / \mathrm{B}_{0}, \%, \mathrm{OY}$ axis $-\mathrm{CW}$ in liquid phase, $\mu \mathrm{L}$ (Figure 5)) crossing the line drawn through a point $50 \%$ on the axis OY parallel to the axis OX.

Typical data of mediated competitive ELISA are shown in Figure 5 by giving strain $L l 132$ grown in medium 2 as an example. The mediator was a solution containing $\mathrm{Ig}_{\text {anti- } L l ~ 493}$, which was first in contact with antigens of CW (1st stage of ELISA) and then - with immobilized antigens of CFF (2nd stage of ELISA). Similar curves were obtained for each of the 4 strains grown in medium 1 and medium 2 (data not shown).

The data was processed as follows. The amount of $\mathrm{CW}$ suspension (in $\mu \mathrm{L}$ ) corresponding to the experimental point with $\mathrm{OY}$ value of $50 \%$ was determined on each graph for each of the three curves; the values obtained were denoted $\mathrm{x}_{1}$ $\mathrm{x}_{3}$ where $1-3$ are $12 \mathrm{~h}-48 \mathrm{~h}$ of culture growth, respectively. The values $1 / \mathrm{x}_{1}$ $1 / x_{3}$ were calculated. The maximum of three values $1 / x_{n}$ was taken as $100 \%$ and the other two values $1 / \mathrm{x}_{\mathrm{n}}$ were converted into percentages. Calculated $1 / \mathrm{x}_{\mathrm{n}}$ values proportional to the $C_{\mathrm{sp}}$ of $\mathrm{CW}$ antigens (per cell) were presented in the form of histograms in Figure 4, CW.

The data shown in Figure 4, CW suggest that the dynamics of $C_{\mathrm{sp}}$ (per cell) of $\mathrm{CW}$ antigens depends on the strain and culture medium. The reason for the increase in $C_{\mathrm{sp}}$ (per cell) of $\mathrm{CW}$ antigens is their synthesis. The reason for the decrease in $C_{\mathrm{sp}}$ (per cell) of $\mathrm{CW}$ antigens is secondary secretion, i.e. migration of $\mathrm{CW}$ components to the medium as the cells age.

\section{The time dependence of $C_{s p}$ (calculated per cell) of secretory antigens}

To compare the dynamics of $C_{\mathrm{sp}}$ (calculated per cell) of secretory antigens of 4 strains of lactococci, the following approach was used. CFF specimens of 4 strains $(\mathrm{n}=24)$ were immobilized from a solutions with pre-selected values of $A_{260 \mathrm{~nm}, 1 \mathrm{~cm}}$ equal to 0.025 in a separate series of wells; total 24 series of wells. 

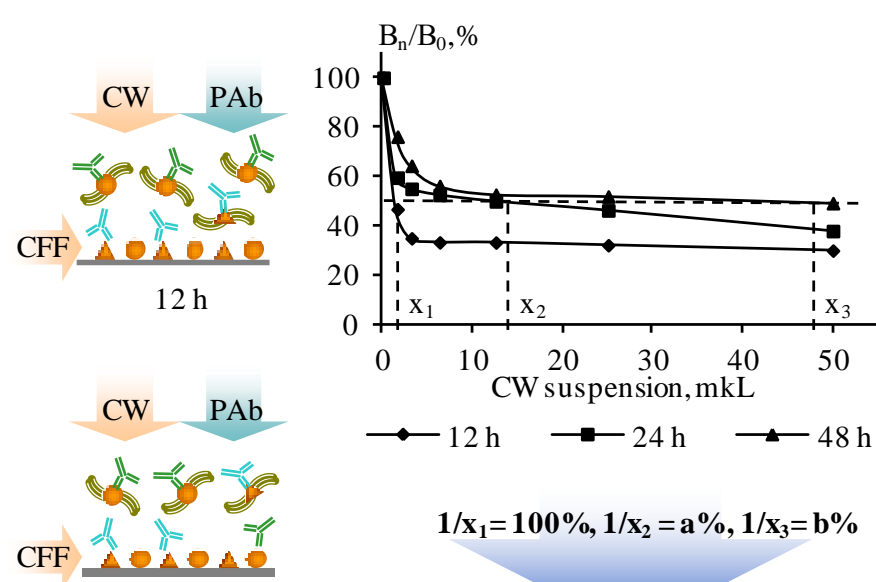

$24 \mathrm{~h}$

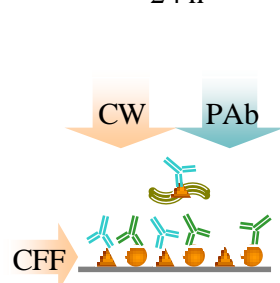

$48 \mathrm{~h}$

$1 / x_{1}=100 \%, 1 / x_{2}=a \%, 1 / x_{3}=b \%$

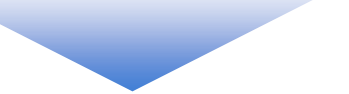

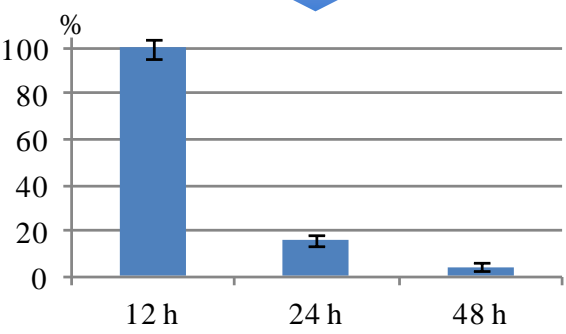

Figure 5 The time dependence of $C_{\mathrm{sp}}$ (calculated per cell) of $\mathrm{CW}$ antigens: design of mediated competitive ELISA, experimental data and their processing. Strain $\mathrm{Ll} 132$ grown in medium 2 was used as an example. Term PAb means

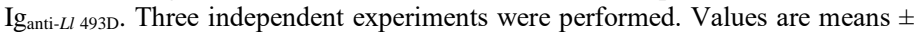
$\mathrm{SD}$.

Each lyophilized CL specimen $(\mathrm{n}=24)$ was dissolved in $300 \mu$ of distilled wate immediately before the assay to obtain 10 -fold CL concentrate designated $10 \times$ CL. For each of the $24 \mathrm{CFF}$ specimens, the corresponding $10 \times \mathrm{CL}$ specimen was used to prepare samples $\left(\mathrm{B}_{0} ; \mathrm{B}_{1}-\mathrm{B}_{5}\right)$ containing $(0 ; 25-400) \mu \mathrm{L} 10 \times \mathrm{CL}$ per 1 $\mathrm{mL}$, respectively. Samples $\left(\mathrm{B}_{0} ; \mathrm{B}_{1}-\mathrm{B}_{5}\right)$ were added into appropriate wells, $50 \mu \mathrm{L}$ per well. Ig anti-Ll 493D $(15 \mu \mathrm{g} / \mathrm{mL}$ in buffer $3 ; 50 \mu \mathrm{L}$ per well $)$ were added to each well of all series and incubated. The amount of immune complexes immobilized antigen - $\mathrm{Ig}_{\text {anti- } L I \text { 493D }}$ was inversely to the amount of antigens in CL specimens.

The value of $A_{260 \mathrm{~nm}, 1 \mathrm{~cm}}$ in solution for immobilization of CFF specimens, $\operatorname{Ig}_{\text {anti- } L}$ 493D concentration and the volumes of $10 \times \mathrm{CL}$ specimens per well were preselected based on the results of preliminary experiments. The criterion of selection was obtaining classical curves of competitive ELISA (in coordinates OX axis $-\mathrm{B}_{\mathrm{n}} / \mathrm{B}_{0}, \%$, OY axis $-\mathrm{CL}$ in liquid phase, $\mu \mathrm{L}$ (Figure 6)) crossing the line drawn through a point $50 \%$ on the axis OY parallel to the axis OX.

Typical data are shown in Figure 6 using strain $L l 132$ grown in medium 2 as an example. Similar curves illustrating competition of secretory antigens (from CL) with immobilized antigens (from CFF) for binding with $\operatorname{Ig}_{\text {anti- } L l \text { 493D }}$.were obtained for each of the 4 strains grown in medium 1 and medium 2 (data not shown).
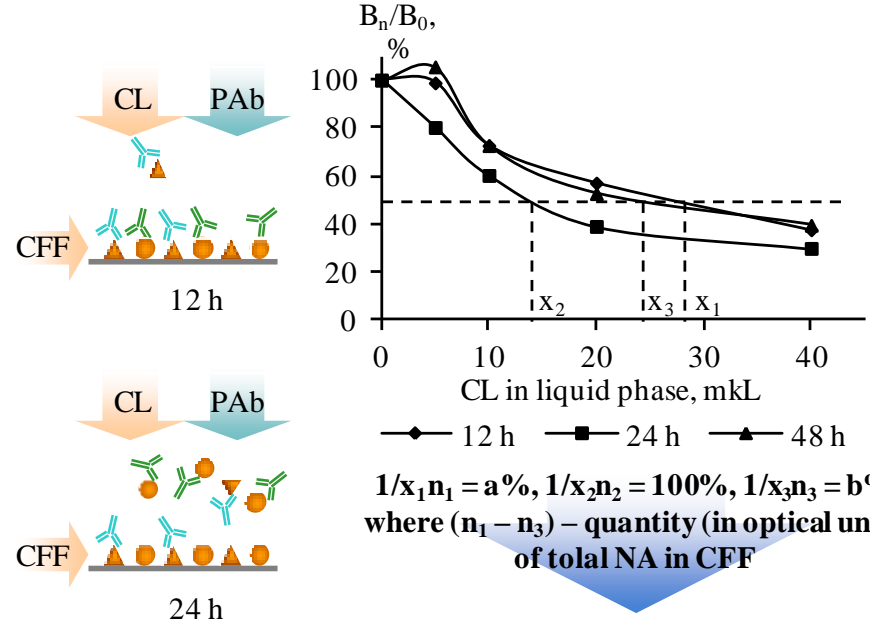

$1 / \mathbf{x}_{1} \mathbf{n}_{1}=a \%, 1 / \mathbf{x}_{2} n_{2}=100 \%, 1 / \mathbf{x}_{3} n_{3}=b \%$, where $\left(n_{1}-n_{3}\right)$ - quantity (in optical units) of tolal NA in CFF
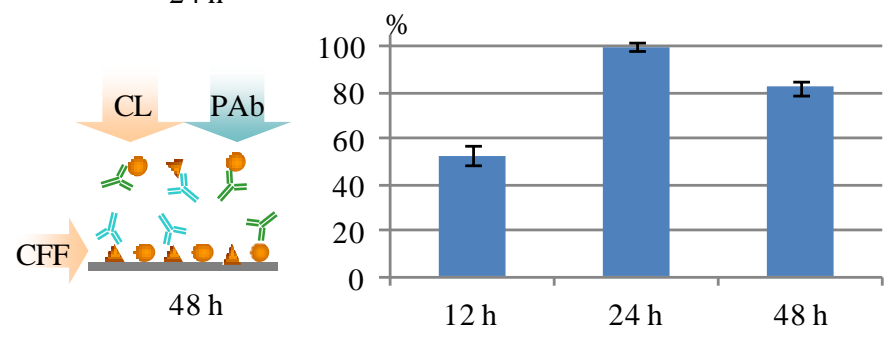

Figure 6 The time dependence of $C_{\mathrm{sp}}$ (calculated per cell) of CL antigens: design of competitive ELISA, experimental data and their processing. Strain $L l 132$

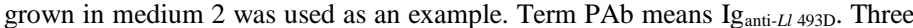
independent experiments were performed. Values are means \pm SD.

The data was processed as follows. The amount of $10 \times \mathrm{CL}$ (in $\mu \mathrm{L}$ ) corresponding to the experimental point with an $\mathrm{OY}$ value of $50 \%$ was determined on each graph for each of the three curves; the values obtained were denoted $x_{1}-x_{3}$ where $1-3$ are $12 \mathrm{~h}-48 \mathrm{~h}$ of culture growth, respectively. The values $1 / \mathrm{x}_{1}-1 / \mathrm{x}_{3}$ were calculated. The maximum of $1 / \mathrm{x}_{\mathrm{n}}$ values was taken as $100 \%$ and the other two $1 / x_{n}$ values were converted into percentages. Each of the $1 / x_{n}$ values was divided by the tNA in the corresponding CFF specimen to "equalize" the number of cells that were used as a source of antigens contained in the CL. Calculated values proportional to the $C_{\mathrm{sp}}$ of secretory antigens (per cell) were presented in the form of histograms in Figure 4, CL.

The data shown in Figure 4, CL suggest that the dynamics of $C_{\mathrm{sp}}$ (per cell) of CL antigens is more dependent on the culture medium than on the strain.

\section{Interpretation of the results}

In the paragraph, the reasons for the increase in antigen concentration in CL are discussed.

Quantitative characteristics of CFF specimens and CW specimens, obtained as a result of cultivation of 4 Lactococcus lactis strains for 12, 24 or $48 \mathrm{~h}$, destruction of cells by ultrasound and centrifugation were shown in Figure 2. As mentioned above, amount of tNA (in conventional units) is proportional to the number of bacterial cells, CW weight (in $\mathrm{mg}$ ) is a function of the number of bacterial cells and the thickness of the cell wall.

The value of each of the two parameters can increase $(\uparrow)$, decrease $(\downarrow)$ or remain unchanged (const). Thus, 9 combinations of changes in two parameters are theoretically possible; 6 of them were actually observed (Table 2). Each of these combinations corresponds to a quite specific reason for the increase in $C_{\mathrm{sp}}$ (per cell) of CL antigens (Table 2).

Table 2 Possible explanation of the increase in $C_{\mathrm{sp}}$ (per cell) of CL antigens Combinations of changes in two Designation $^{2} \quad$ The reasons why antigens in $\mathrm{CFF}$ and the weight of $\mathrm{CW}^{1} \quad$ occur in $\mathrm{CL}$

\begin{tabular}{|c|c|c|c|}
\hline 1 & tNA $\uparrow, \mathrm{CW}$ const & $1 \mathrm{a}$ & \multirow{2}{*}{ Primary (natural) secretion } \\
\hline 2 & tNA const, $\mathrm{CW} \uparrow$ & $1 \mathrm{~b}$ & \\
\hline 3 & $\mathrm{tNA} \uparrow, \mathrm{CW} \downarrow$ & $2 \mathrm{a}$ & \multirow{2}{*}{$\begin{array}{c}\text { Secondary secretion } \\
\text { (migration of CW components } \\
\text { to CL as cells age) }\end{array}$} \\
\hline 4 & tNA const, $\mathrm{CW} \downarrow$ & $2 b$ & \\
\hline 5 & tNA $\downarrow, \mathrm{CW} \uparrow$ & $3 a$ & \multirow{2}{*}{$\begin{array}{l}\text { Secondary secretion or cell } \\
\text { death }\end{array}$} \\
\hline 6 & tNA $\downarrow, \mathrm{CW} \downarrow$ & $3 b$ & \\
\hline
\end{tabular}
CL

There are two comments to Figure 4, CL, supplementing the Table 1. At first, the 
primary secretion of antigens could occur up to $12 \mathrm{~h}$, in a period corresponding to the logarithmic phase of culture growth. At second, the decrease in the $C_{\mathrm{sp}}$ (per cell) of CL antigens at $(24-48) \mathrm{h}$ observed after its increase at $(12-28) \mathrm{h}$ in medium 2 (Figure 4, CL) can be explained by two reasons: $(i)$ in CL, the antigens lose their native structure and the ability to interacts with antibodies (for example, as result of proteolysis by extracellular proteases (Addi and Guessas, 2016)) and, therefore, can't be detected using $\operatorname{Ig}_{\text {anti- } L l ~ 493 \mathrm{D}}$, (ii) an increase in the number of cells occurred, but increase in cell wall thickness was limited by depleted environmental resources (Figure 2, strains $\mathrm{Ll} \mathrm{493D,} \mathrm{Ll} \mathrm{922).}$

\section{CONCLUSION}

We elaborated the methodology for studing the time dependence of specific concentration $\left(C_{\mathrm{sp}}\right)$ (calculated per cell) of the biopolymer of interest in cell fractions and culture media. Using 4 strains of Lactococcus lactis and $\mathrm{PAb}_{\mathrm{ant}-\mathrm{L}}$ 493D as an example, we show that $C_{\text {sp }}$ of lactococcal antigens in cell fractions and culture media depends on strain, media composition and duration of culture growth. Distribution of antigens between cell fractions and media and timedependance of $C_{\mathrm{sp}}$ is unpredictable and for each strain/media should be determined individually.

The methodology is suitable for any bacterium and any well-defined antigen under the condition that either PAb or mouse monoclonal antibodies specific for this antigen will be used.

The methodology will find an application in research studies and biotechnology to optimize biotechnological processes via selection of the strain producing the biolimer of interest, localization of the target biopolymer (cell fraction/media) and selection of duration of culture growth and media composition providing maximum yeald.

Acknowledgeents. This work was supported by the Belarusian Republican Foundation for Fundamental Research (grant B16R-056) and Russian Foundation for Basic Research (grant 16-54-00081-Bel_a).

\section{REFFERENCES}

Addi, N., Guessas, B. (2016). Characterization of protease activity of Lactococcus lactis species isolated from raw camel's milk. Journal of Biological Sciences, 16, 215-220. http://dx.doi.org/10.3923/jbs.2016.215.220

Adrio, J. L., Demain, A. L. (2014). Microbial enzymes: tools for biotechnologica processes. Biomolecules, 4(1), 117-139. https://doi.org/10.3390/biom4010117

Ai, C., Zhang, Q., Ren, C., Wang, G., Liu, X., Tian, F., Zhao, J., Zhang, H., Chen, Y.Q., Chen, W. (2014). Genetically engineered Lactococcus lactis protect against house dust mite allergy in a BALB/c mouse model. PLOS ONE, 9(10), e109461. https://doi.org/10.1371/journal.pone.0109461

Asensi, G. F., de Sales, N. F. F., Dutra, F. F., Feijó, D. F. (2013). Oral immunization with Lactococcus lactis secreting attenuated recombinant staphylococcal enterotoxin B induces a protective immune response in a murine model. Microbial Cell Factories, 12, 32. https://doi.org/10.1186/1475-2859-12$\underline{32}$

Balciunas, E. M., Martinez, F. A. C., Todorov, S. D., de Melo Franco, B. D. G., Converti, A., de Souza Oliveira, R. P. (2013). Novel biotechnological applications of bacteriocins: a review. Food Control., 32(1), 134-142. https://doi.org/10.1016/j.foodcont.2012.11.025

Braat, H., Rottiers, P., Hommes, D. W., Huyghebaert, N., Remaut, E., Remon, J. P., van Deventer, S. J., Neirynck, S., Peppelenbosch, M. P., Steidler, L. (2006). A phase I trial with transgenic bacteria expressing interleukin-10 in Crohn's disease. Clin Gastroenterol Hepatol, 4(6), 754 - 759. http://dx.doi.org/10.1016/j.cgh.2006.03.028

Chikindas, M. L., Weeks, R., Drider, D., Chistyakov, V. A., Dicks, L. M. (2017) Functions and emerging applications of bacteriocins. Curr Opin Biotechnol., 49, 23-28. https://doi.org/10.1016/j.copbio.2017.07.011

Coffey, A., Ross, R. P. (2002) Bacteriophage-resistance systems in dairy starter strains: molecular analysis to application. Antonie Van Leeuwenhoek, 82(1-4), 303-321. https://doi.org/10.1023/A:1020639717181

D’Souza, R., Pandeya, D. R., Rahman, M., Lee, H. S., Jung, J.-K., Hong, S.-T. (2012). Genetic engineering of Lactococcus lactis to produce an amylase inhibitor for development of an anti-diabetes biodrug. New Microbiologica, 35, 35-42.

Ezubets, A.P., Kiseleva, E.P., Koloźyn-Krajewska, D., Novik, G.I. (2014) Polyclonal rabbit antibodies to antigens of Lactococcus lactis BIM B-493 D: production, testing and properties. Vestsi NAS of Belarus, Special Issue, 32 - 36 (in russian).

Frantzen, C. A., Kleppen, H. P., Holo, H. (2017). Diversity of Lactococcus lactis in undefined mixed dairy starter cultures revealed by comparative genome analyses and targeted amplicon sequencing of epsD. Applied and Environmental Microbiology, https://doi.org/10.1128/AEM.02199-17

Frece, J., Cvrtila, J., Topić, I., Delaš, F., Markov, K. (2014). Lactococcus lactis ssp. lactis as a functional starter culture. Food Technol. Biotechnol., 52(4), 489494. https://dx.doi.org/10.17113/ftb.52.04.14.3794
Gurung, N., Ray, S., Bose, S., Rai, V. (2013). A broader view: microbial enzymes and their relevance in industries, medicine, and beyond. BioMed Research International., 2013, Article ID 329121. http://dx.doi.org/10.1155/2013/329121

Heilig, H. G., Zoetendal, E. G., Vaughan, E. E., Marteau, P., Akkermans, A. D. de Vos, W. M. (2002). Molecular diversity of Lactobacillus spp. and other lactic acid bacteria in the human intestine as determined by specific amplification of $16 \mathrm{~S}$ ribosomal DNA. Appl. Environ. Microbiol., 68(1), 114-123. https://dx.doi.org/10.1128/AEM.68.1.114-123.2002

Hermanson, G. T. Bioconjugate Techniques, 2nd ed., Elsevier: London, 2008; p. 745-782..

Hols, P., Kleerebezem, M., Schanck, A., Ferain, T., Hugenholtz, J., Delcour, J., de Vos, W. M. (1999). Conversion of Lactococcus lactis from homolactic to homoalanine fermentation through metabolic engineering. Nature Biotechnology, 17(6), 588-592. https://doi.org/10.1038/9902

Jozala, A. F., de Lencastre Novaes, L. C., Cholewa, O., Moraes, D., Penna, T. C. V. (2005). Increase of nisin production by Lactococcus lactis in different media. African Journal of Biotechnology, 4(3), 262-265. Available online at http://www.academicjournals.org/AJB

Kelly, W. J., Ward, L. J. H., Leahy, S. C. (2010). Chromosomal diversity in Lactococcus lactis and the origin of dairy starter cultures. Genome Biol. Evol., 2, 729-744. https://doi.org/10.1093/gbe/evq056

Kiseleva, E., Mikhailopulo, K., Ladutska, A., Novik, G. (2017). Methodological approach to the study of dynamics of specific concentration of cell wall antigens per cell of Bacillus species and examples of its application. EuroBiotech Journal., 1(1), 71 - 77. https://doi.org/10.24190/ISSN2564-615X/2017/01.10

López-Cuellar, M. R., Rodríguez-Hernández, A.-I., Chavarría-Hernández, N. (2016). LAB bacteriocin applications in the last decade. Biotechnology \&

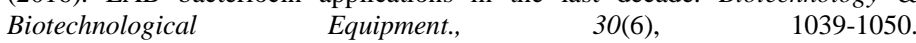
https://doi.org/10.1080/13102818.2016.1232605

Medina, M., Vintiñi, E., Villena, J., Raya, R., Alvarez, S. (2010). Lactococcus lactis as an adjuvant and delivery vehicle of antigens against pneumococcal respiratory infections. Bioengineered Bugs, 1(5), 313-325. https://doi.org/10.4161/bbug.1.5.12086

Perosa, F., Carbone, R., Ferrone, S., Dammacco, F. (1990). Purification of human immunoglobulins by sequential precipitation with caprylic acid and ammonium sulphate. J. Immunol. Methods., 128(1), 9-16. https://doi.org/10.1016/00221759(90)90458-8

Singh, R., Kumar, M., Mittal, A., Mehta, P. K. (2016). Microbial enzymes: industrial progress in 21st century. 3 Biotech., 6, 174 https://doi.org/10.1007/s13205-016-0485-8

Shigemori, S., Namai, F., Yamamoto, Y., Nigar, S., Sato, T., Ogita, T., Shimosato, T. (2017). Genetically modified Lactococcus lactis producing a green fluorescent protein-bovine lactoferrin fusion protein suppresses proinflammatory cytokine expression in lipopolysaccharide-stimulated RAW 264.7 cells. J. Dairy Sci., 100, 7007-7015. https://doi.org/10.3168/jds.2017-12872

Vijayakumar, S., Saravanan, V. (2015). Biosurfactants-types, sources and applications. Research Journal of Microbiology, 10(5), 181-192. http://dx.doi.org/10.3923/jm.2015.181.192

Yadav, K., Bhardwaj, A., Kaur, G., Iyer, R., De, S., Malik, R. K. (2009) Potential of Lactococcus lactis as a probiotic and functional lactic acid bacteria in dairy industry. International Journal of Probiotics and Prebiotics, 4(3), 219-228.

Yang, S.-C., Lin, C.-H., Sung, C. T., Fang, J.-Y. (2014). Antibacterial activities of bacteriocins: application in foods and pharmaceuticals. Frontiers in microbiology, 5, Art. 241. https://doi.org/10.3389/fmicb.2014.00241

Yerlikaya, O. (2014). Starter cultures used in probiotic dairy product preparation and popular probiotic dairy drinks. Food Sci. Technol. (Campinas), 34(2), 221229. http://dx.doi.org/10.1590/fst.2014.0050 